\title{
Osteoarthritis of the hip and acetabular dysplasia
}

\author{
P Croft, C Cooper, C Wickham, D Coggon
}

\begin{abstract}
The relation between acetabular dysplasia and osteoarthritis of the hip was examined in a series of 1516 pelvic radiographs taken for non-skeletal indications. Osteoarthritis was assessed by measuring joint space, and dysplasia by the centre-edge angle and acetabular depth. In contrast with previous studies of patients with symptomatic osteoarthritis of the hip, no evidence that dysplasia predisposes to osteoarthritis was found. Possible reasons for the discrepancy are discussed. It was concluded that although acetabular dysplasia may lead to osteoarthritis of the hip in some subjects, it is unlikely to be an important cause of the disease in men.
\end{abstract}

A wide variety of disorders predispose to osteoarthritis of the hip, including congenital dislocation or subluxation of the joint, Perthes' disease, slipped upper femoral epiphysis, septic and inflammatory arthritis, trauma, and several metabolic diseases. Between them, however, these established causes account for less than half of all degenerative hip disease. ${ }^{1}$

Dislocation and symptomatic subluxation of the hip form part of a broader spectrum of hip dysplasia and instability in childhood. ${ }^{2}$ It has been proposed that in many patients with apparently primary osteoarthritis of the hip, the disease occurs as a consequence of mild forms of acetabular dysplasia which persist into adult life. Support for this theory comes from radiological observations in patients with osteoarthritis of the hip, ${ }^{3-5}$ and from follow up studies of subjects with dysplastic hips. ${ }^{6}$ Not all studies have shown the association, ${ }^{7}$ however.

To find out more about the relation between acetabular dysplasia and osteoarthritis of the hip we examined their association in a sample of pelvic radiographs taken for non-skeletal indications.

Southampton

Southampton General

Hospital,

Southampton SO9 4XY

$P$ Croft

C Wickham

D Coggon

Rheumatology Unit,

Department of Medicine, Bristol Royal Infirmary, Bristol BS2 8HW C Cooper

Correspondence to: Dr P Croft,

ARC Epidemiology Research

Unit, Stopford Building,

(University of Manchester),

Oxford Road

Manchester M13 9PT.

Accepted for publication

18 April 1990

The study was carried out in the outpatien radiology department of the North Staffordshire hospitals. From the $x$ ray register we identified all men who had had an intravenous urogram during 1982-87 and who were aged 60-75 years at the time of examination. Their hip joints were then assessed from the control or postmicturition film. Radiographs were excluded if neither hip could be adequately visualised. If a patient had been examined more than once during the study period the earliest suitable radiograph was used. Where hips had been replaced before the earliest suitable intravenous urogram, preoperative radiographs were assessed if available.

One observer (PC) read all the radiographs. Osteoarthritis was evaluated by measuring the shortest distance between the femoral head margin and the acetabulum (the minimal joint space), and the position of maximal joint space narrowing was noted. Acetabular dysplasia was assessed by two measures: the centre-edge angle $^{8}$ and the acetabular depth ${ }^{3}$ (fig 1). The former was defined as the angle between a line joining the centre of the femoral head to the lateral margin of the acetabular roof and a line perpendicular to that joining the centres of the two femoral heads. The centres of the femoral heads were located with the aid of a transparent plastic sheet marked with concentric circles. If the femoral head was deformed the plastic sheet was aligned in relation to unaffected areas. In locating the lateral margin of the acetabular roof we took account of any osteophytosis. Acetabular depth was defined as the greatest perpendicular distance from the acetabular roof to a line joining the lateral margin of the acetabular roof and the upper corner of the symphysis pubis on the same side. In the presence of acetabular dysplasia the centre-edge angle and acetabular depth are both low.

To assess the repeatability of the measurements a subset of 50 films was reread by the same observer at an interval of three months, and again, independently, by a second observer (CC). All markings were erased between the readings.

\section{Results}

Intravenous urograms showing the hip joints were available for 1315 of the 1516 men identified from the $x$ ray register, but nine hips could not be assessed because they had previously been replaced (six) or were severely deformed by Paget's disease (three). In addition, not all views were adequate for the measurement of minimal joint space (three hips), centreedge angle (17 hips), or acetabular depth (64 hips).

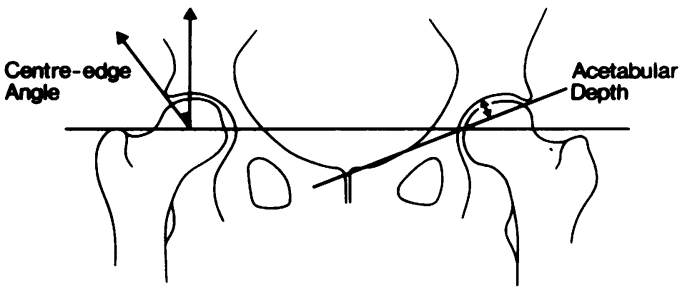

Figure I Measurements of acetabular dysplasia. 
Table 1 Distribution of centre-edge angles according to minimal joint space

\begin{tabular}{|c|c|c|c|c|c|c|}
\hline & \multirow{2}{*}{$\begin{array}{l}\text { No of hips } \\
\text { assessed }\end{array}$} & \multicolumn{3}{|c|}{ Centre-edge angle (deg) } & \multicolumn{2}{|c|}{ No (\%) of hips } \\
\hline & & Mean & Median & $\begin{array}{l}\text { Standard } \\
\text { deviation }\end{array}$ & $<25^{\circ}$ & $\leqslant 20^{\circ}$ \\
\hline $\begin{array}{l}\text { All hips } \\
\text { Hips with minimal joint space } \geqslant 4.0 \mathrm{~mm} \\
\text { Hips with minimal joint space } \leqslant 1.5 \mathrm{~mm}\end{array}$ & $\begin{array}{r}2604 \\
1076 \\
47\end{array}$ & $\begin{array}{l}36 \cdot 2 \\
34 \cdot 0 \\
42 \cdot 3\end{array}$ & $\begin{array}{l}36 \cdot 0 \\
34 \cdot 0 \\
42 \cdot 0\end{array}$ & $\begin{array}{r}6 \cdot 9 \\
6 \cdot 2 \\
10 \cdot 4\end{array}$ & $\begin{aligned} 94(3 \cdot 6) \\
58(5 \cdot 4) \\
2(4 \cdot 3)\end{aligned}$ & $\begin{array}{r}26(1 \cdot 0) \\
17(1 \cdot 6) \\
1(2 \cdot 1)\end{array}$ \\
\hline
\end{tabular}

Table 2 Distribution of acetabular depth according to minimal joint space

\begin{tabular}{|c|c|c|c|c|c|}
\hline & \multirow{2}{*}{$\begin{array}{l}\text { No of hips } \\
\text { assessed }\end{array}$} & \multicolumn{3}{|c|}{ Acetabular depth (mm) } & \multirow{2}{*}{$\frac{\text { No (\%) of hips }}{<9 \mathrm{~mm}}$} \\
\hline & & Mean & Median & $\begin{array}{l}\text { Standard } \\
\text { deviation }\end{array}$ & \\
\hline $\begin{array}{l}\text { All hips } \\
\text { Hips with minimal joint space } \geqslant 4.0 \mathrm{~mm} \\
\text { Hips with minimal joint space } \leqslant 1.5 \mathrm{~mm}\end{array}$ & $\begin{array}{r}2557 \\
1057 \\
45\end{array}$ & $\begin{array}{l}14 \cdot 4 \\
14 \cdot 1 \\
15 \cdot 8\end{array}$ & $\begin{array}{l}14 \cdot 0 \\
14 \cdot 0 \\
15 \cdot 0\end{array}$ & $\begin{array}{l}3 \cdot 1 \\
3 \cdot 1 \\
4 \cdot 4\end{array}$ & $\begin{array}{l}54(2 \cdot 1) \\
31(2 \cdot 9) \\
0(0)\end{array}$ \\
\hline
\end{tabular}

Minimal joint space was distributed unimodally with mean $3.5 \mathrm{~mm}$, median $3.5 \mathrm{~mm}$, and standard deviation $0.9 \mathrm{~mm}$. Fifty three hips $(2 \cdot 0 \%)$ showed severe joint space narrowing (minimal joint space $\leqslant 1.5 \mathrm{~mm}$ ). These were compared with the 1078 hips $(41 \cdot 2 \%)$ with a minimal joint space $\geqslant 4.0 \mathrm{~mm}$.

Centre-edge angle and acetabular depth were linearly related (correlation coefficient $=0 \cdot 73$ ). Tables 1 and 2 summarise their distribution in relation to joint space. In hips with a minimal joint space $\geqslant 4.0 \mathrm{~mm}$ the mean centre-edge angle was $34.0^{\circ}\left(\mathrm{SD} 6.2^{\circ}\right)$ and the mean acetabular depth $14 \cdot 1 \mathrm{~mm}$ (SD $3 \cdot 1 \mathrm{~mm})$. The prevalence of low centre-edge angles (less than $25^{\circ}$ ) was little different in hips with a minimal joint space $\leqslant 1.5 \mathrm{~mm}$ from that in hips with a minimal joint space $\geqslant 4.0 \mathrm{~mm}$. No hips with severe joint space narrowing had an acetabular depth less than $9 \mathrm{~mm}$.

Figure 2 illustrates further the relation of joint space to centre-edge angle and acetabular depth. For both measures of acetabular dysplasia the correlations with minimal joint space were weakly negative. This pattern was apparent whether lateral osteophytosis of the acetabular margin was present (598 hips) or absent.

The most common positions of maximal joint space narrowing were superomedial (1869 hips), superolateral (416 hips), and both superomedial and superolateral (309 hips). There was no indication of an association between joint space narrowing and acetabular dysplasia in any of these subsets of hips.
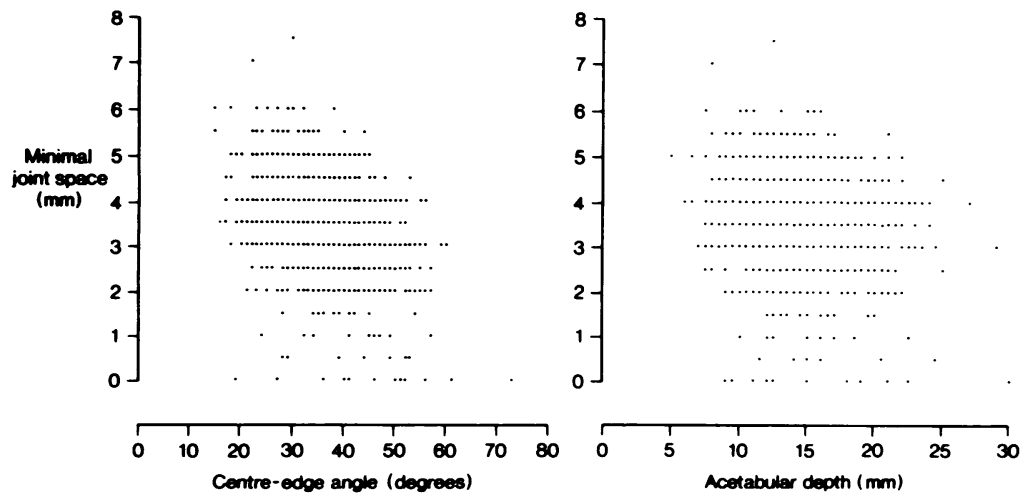

Figure 2 Relation of minimal joint space to centre-edge angle $(r=-0 \cdot 37)$ and acetabular $\operatorname{depth}(r=-0 \cdot 15)$.
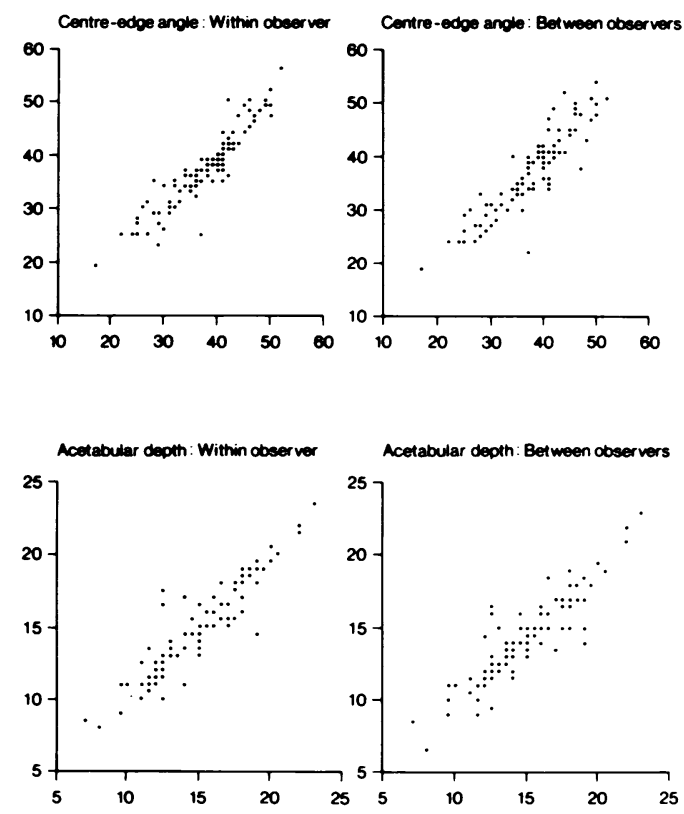

Figure 3 Repeatability of measurements of acetabular dysplasia within and between observers.

Preoperative radiographs were obtained for five of the six hips that had been replaced. In two hips (both in the same patient) the centreedge angle was less than $20^{\circ}$ and the acetabular depth less than $9 \mathrm{~mm}$.

Figure 3 shows the repeatability of acetabular measurements. Agreement was good both within and between observers.

\section{Discussion}

We found no evidence in this survey of male urology patients to support the hypothesis that osteoarthritis of the hip is associated with acetabular dysplasia. This contrasts with the conclusions from most previous studies. ${ }^{3-6}$

We think it unlikely that the discrepancy can be explained by errors in our measurements. We have already established the validity of minimal joint space as an index of osteoarthritis of the hip. ${ }^{8 a}$ It correlates with other radiological features of the disease and with symptoms, and is more reproducible than composite assessments of the type devised by Kellgren and Lawrence. ${ }^{9}$ The repeatability of measurements 
of acetabular dysplasia has not been reported before, but in this study agreement was good both within and between observers. The radiographs studied were taken with the same tube to film distance $(100 \mathrm{~cm})$ as a standard anteroposterior view of the pelvis, but centred about $10 \mathrm{~cm}$ higher in the midline. The distortion arising from this difference in projection would not affect the ranking of linear measurements or angles, and should only be small. In support of this the distributions of centre-edge angle and acetabular depth which we recorded in hips with a minimal joint space $\geqslant 4 \mathrm{~mm}$ are similar to those reported by other observers in asymptomatic controls. ${ }^{34810}$ Leg position is not standardised for an intravenous urogram, and rotation of the hip may influence the centreedge angle, but again the effect is small. ${ }^{8}$

Possibly, measures of acetabular dysplasia are modified by the osteoarthritic process. For example, osteophytosis might make it difficult to locate correctly the lateral acetabular margin, and medial migration of the femoral head may increase the centre-edge angle. Our findings were unaltered, however, when hips with lateral osteophytes were excluded from the analysis, and medial migration should not have affected acetabular depth. Moreover, any masking of acetabular dysplasia caused by osteoarthritis would apply also to other studies which examined the relation of osteoarthritis of the hip to acetabular dysplasia retrospectively.

The divergence from other studies lies in the prevalence of acetabular dysplasia in osteoarthritic hips. In 47 hips with severe joint space narrowing we found only two with a centre-edge angle less than $25^{\circ}$ and none with an acetabular depth less than $9 \mathrm{~mm}$. Other investigators have reported higher prevalence.

In two studies the higher prevalence of dysplasia occurred in women, but in men the prevalence was little different from that which we found. Defining dysplasia as a centre-edge angle less than $25^{\circ}$ or an acetabular depth less than $9 \mathrm{~mm}$, Murray found a prevalence of $5 \cdot 6 \%$ in the hips of 90 men with unilateral or bilateral primary osteoarthritis. ${ }^{3}$ The prevalence in diseased hips as compared with unaffected hips was not stated. Data reported by Solomon from South Africa indicate a prevalence of about $5 \%$ in male osteoarthritic hips, but the exact criteria by which he diagnosed dysplasia are unclear. ${ }^{5}$ Given such uncertainties and the small numbers on which the prevalence estimates are based, neither of these studies is incompatible with our findings.

Harder to reconcile is the description by Stulberg and colleagues of acetabular dysplasia in 13 out of 53 men presenting consecutively for reconstructive hip surgery. ${ }^{4}$ Their method of assessing dysplasia was different from ours, but they state that $80 \%$ of their dysplastic hips had a centre-edge angle of $20^{\circ}$ or less. Possibly the explanation for the differences lies in the selection of subjects for study. Their series included patients from a wider age range than ours, and all had disease sufficient to warrant an operation. Only four men in our sample had undergone hip replacement, and one of these had bilateral dysplasia preoperatively. It may be, therefore, that dysplasia is associated specifically with more severe and rapidly progressive disease. In the only other cross sectional study to examine the relation of dysplasia to osteoarthritis of the hip no association was apparent. ${ }^{7}$

Only one investigation has examined the influence of dysplasia on osteoarthritis prospectively. At the Norrbacka Institute in Stockholm 20 patients, whose old radiographs showed a centre-edge angle $\leqslant 20^{\circ}$ but no evidence of dislocation, were re-examined at a mean interval of 22 years from presentation. ${ }^{6}$ At follow up 21 of 32 dysplastic hips had severe osteoarthritis and nine showed moderate degeneration. Ten of the hips were in men, and, of these, eight had severe and two had moderate osteoarthritis. The main weakness of this study was the possibility of bias due to the loss of patients whose old records were unavailable. Its strength was that dysplastic changes were shown on radiographs taken before the development of osteoarthritis of the hip. Thus they could not be attributed to an artefact of the osteoarthritic process.

On the balance of evidence we would not dismiss the possibility that acetabular dysplasia predisposes to osteoarthritis of the hip in some subjects. Our data suggest, however, that in men only a small proportion of all osteoarthritis of the hip is likely to result from dysplasia. It may be a more important cause of the disease in women, though the reasons for such a sex difference are not obvious. In control series the prevalence of dysplasia has not been markedly higher in women than in men. 34810

PC was in receipt of a training fellowship from the Wellcome Foundation. We thank Dr R B Cole of the Industrial and Community Health Research Centre, Stoke-on-Trent, Dr R O Murray, Mrs Lisa Walmsley-Pitts, and the staff of the radiology and records department of the North.Staffordshire Health authority.

1 Lloyd-Roberts G C. Osteoarthritis of the hip. $\mathcal{F}$ Bone foint Surg [Br] 1955; 37: 8-47.

2 Weinstein S L. Natural history of congenital hip dislocation CDH) and hip dysplasia. Clin Orthop 1987; 225: 62-76. Murray $\mathrm{R} \mathrm{O}$. The aetiology of primary osteoarthritis of the hip. Br F Radiol 1965; 38: 810-24.

4 Stulberg S D, Harris W H. Acetabular dysplasia and development of osteoarthritis of the hip. In: Harris W $\mathbf{H}$ development of osteoarthris of the hip. ed. The hip. Proceedings of the second open scientific m.

5 the Hip Society. St Louis: Mosby, 1974: 82-93. Surg [Br] 1976; 58: 176-83.

6 Cooperman D R, Wallensten R, Stulberg S D. Acetabula dysplasia in the adult. Clin Orthop 1983; 175: 79-85.

7 Zinn W M. Reflections on degenerative hip disease. Annals of Physical Medicine 1970; 10: 209-17.

8 Wiberg G. A measuring method for distinguishing between normal and a maldeveloped acetabulum. Acta Chir Scand 1939; 83 (suppl 58): 28-38.

8a Croft P, Cooper C, Wickham C, Coggon D. Defining osteoarthritis of the hip for epidemiologic studies. Am $f$ Epidemiol 1990; 132: 514-22.

9 Kellgren J H, Lawrence J S. Radiological assessment of osteoarthrosis. Ann Rheum Dis 1957; 16: 494-502.

10 Fredensborg N. The CE angle of normal hips. Acta Orthop Scand 1976; 47: 403-5. 